An Intraweek Seasonality in the Implied Volatilities of Individual ...

Morse, Joel N

The Financial Review; Aug 1991; 26, 3; ABI/INFORM Global

pg. 319

The Financial Review $\quad$ Vol. 26 No. 3 August 1991 Pp. 319-341

\title{
An Intraweek Seasonality in the Implied Volatilities of Individual and Index Options
}

\author{
Joel N. Morse*
}

\begin{abstract}
This paper studies intraweek seasonalities in the implied volatilities of options on stock market indices. Oneway analysis of variance isolates the daily behavior of implied volatilities. The differential between call implied volatility and put implied volatility tends to drop on Friday and rise on Monday. Relying on a synthetic futures contract created from options, an explanatory model is proposed. The model complements previous research on the difference between the intraweek behavior of stock market indices and that of derivative instruments based on the indices.
\end{abstract}

\section{Introduction}

Stock market returns are generally negative on Mondays. It is puzzling that the same anomalous behavior is difficult to confirm in the stock index derivatives market.

This paper studies intraweek seasonalities in the implied volatilities of call and put options on stock market indices and (peripherally) on individual stocks. This may help explain the divergent intraweek patterns observed for the cash markets in equities and derivative instruments based on stock market indices. A model is proposed that relates synthetic stock index futures contracts composed of stock index options to this intermarket divergence. The results are relevant to investors who use derivative instruments to transfer risk, to scholars of market efficiency, and to regulators who must assess the usefulness of these markets.

*University of Baltimore, Baltimore, MD 21201-5779. I thank two anonymous referees as well as the participants in the University of Baltimore Finance Seminar for helpful comments. Financial support was received from the University of Baltimore Educational Foundation. I am grateful to Goldman Sachs for data. 
Research to date on intraweek regularities covers diverse markets in various institutional settings. In the fixed-income area, Poole [42] and Eisemann and Timme [18] discuss the micromechanics of the Federal Reserve System and the Federal funds market. Stigum [47] and Melton [37] provide anecdotal evidence of high Friday and Wednesday volatility of the Federal funds rate. Dyl [16] concludes that Friday federal funds rates are on average higher than other days. Spindt and Hoffmeister [45] explain how the mechanics of the Federal funds system lead to high variability of rates on Friday, especially on the second Friday of each reporting period.

In stocks, findings of intraweek regularities have often been accompanied by analysis of particular institutional features or related anomalies (see, for example, Phillips-Patrick and Schneeweis [41] who relate high Monday dividends to the putative Monday effect in stocks, or Jaffe and Westerfield [28, 29] who study the effects of currency seasonals and clearing procedures in the weekend effect context). Finnerty and Park [19] note that spot as well as futures contracts on the Major Market Index begin to rise by 1:30 p.m. on Friday and appear to complete their Monday decline within 30 minutes of the opening. Harris [26] finds that large firms accomplish most of their Monday decline during the first 45 minutes of trading, while small firms continue to move lower throughout the trading day.

A healthy skepticism should prevail in all discussions of intraweek regularities. Using a Bayesian approach, Connally [9] proposes that most reported anomalies of this type are due to incorrect hypothesis testing procedures, unduly large samples, and historical accidents. Dimson [15] devotes a whole book to stock market anomalies. Rystrom and Benson [44] claim that investors feel "blue" on Mondays and buttress this assertion with a search of the behavioral literature and a test of odd-lot ratios. De Gennaro [13] finds that payment delays do not explain the day-of-the-week effect.

Another approach is to attempt to confirm the generality of an effect across diverse asset classes. Such an approach in Flannery and Protopapadakis [21] discovers that across a broad range of equities and bonds Monday returns become increasingly negative with maturity. 
Morse [39] finds evidence of a weekly seasonal in the implied volatilities of U.S. Treasury bond options, which he explains by invoking a duration argument. Implied volatilities rose on Thursdays, fell on Fridays, and rose again on Monday as the Thursday-Friday effect unwound. Day and Lewis [12] find that options impound the cash market volatility around expiration dates. Chiang and Tapley [4] review day-of-the week effects in several U.S. futures markets. Porter [43] believes that 20 percent of the Canadian and U.S. day-of-the-week effect (as well as most of the U-shaped intraday effect) is due to the probability that a trade will occur at the asked price. Peterson [40] demonstrates that calls fall and puts rise after weekends between 1983 and 1985 . CBOT [3] explains how dividend seasonality is recognized by futures markets.

Johnston, Kracaw, and McConnell [30] examine futures contracts on GNMAs, T-bonds, and T-bills. Until 1982, they find that GNMAs and T-bonds show a significant negative return from Friday's close to Monday's close. After 1982, no weekend effect is evident. They did not find this seasonal in the T-bill futures market, which is consistent with Flannery and Protopapadakis' conclusion that the Monday effect is less evident as the maturity of the instrument decreases.

$\mathrm{Ma}, \mathrm{Rao}$, and Weinraub [36] find Monday regularities in the convertible bond market that are similar to those in underlying equity markets. Gay and Kim [24] find a negative Monday effect in the 29-year history of the Commodity Research Bureau Index of 27 futures contracts. This effect disappeared in 1981 when the Economic Recovery Act of 1981 directed futures traders to mark their positions to market at the turn of the year.

Cornell [10] fails to find a Monday effect in the Standard \& Poor's (S\&P) 500 futures contract during the May 1982-July 1984 period. Although this is possibly related to the 1981 Tax Act, Dyl and Maberly [17] suggest that Cornell may have had errors in his records of opening data.

Flannery and Protopapadakis [21] suggest a novel approach that could help explain the generality of weekend effects. Bond prices impound a vector of term premia in the interest rates used to discount future cash flows. 
It is possible that this vector is perturbed before and after the weekend. The risks of holding or shorting assets during periods when markets are closed differs from when the market is open. For example, hedges and delta-neutral strategies cannot be adjusted or arbitraged during a weekend. Huang [27] and Gibbons and Ferson [25] present theories of time-varying risk premia, albeit with only passing reference to the present topic.

An approach to interday differences in the variance of returns is proposed by Foster and Viswasnathan [22, 23]. Adverse selection costs are highest on Monday because information has accumulated without being reflected in prices. Uninformed traders are motivated to delay their trades. The volume rises through the week, and price variance is highest on Monday. Below it will be seen that option implied volatilities (IVs) are highest before and after the weekend. Also, the variance of the IVs is also highest surrounding the weekend.

Ziemba [51] states that Osaka 50 Index futures trading appears to anticipate several intraweek seasonalities in the cash market. Morse [38] shows a correlation between the S\&P 500 Index futures premium and the relative levels of call and put IV in the S\&P 100 Index option. This paper searches for day-of-the-week effects in the IVs of exchange-traded call and put options on four stock market indices. It attempts to explain, by means of a synthetic futures model, the lack of a weekend effect in the traded futures contract. For comparative purposes, 19 individual equities are examined as well. The second section below describes the data. The third section presents a model. The fourth section presents analyses. The fifth section summarizes and suggests areas for future research.

\section{Data}

The sample period is November 19, 1984, through July 10, 1987. As in Flannery and Protopapadakis [21], only one observation per day is available, which makes it impossible to distinguish overnight changes in IV from intraday changes.

The bulk of the data was obtained from various sources including the Wall Street Journal, Goldman 
Sachs, Standard \& Poor's Daily Stock Prices, and Options Research, Inc. The data were randomly crosschecked and examined for internal consistency. Table 1 describes the four market indices. The 19 stocks chosen represent major components of the four market indices and represent approximately 13 industries. Table 2 describes the industry within which each company operates and lists its contribution to the composition of the four indices.

IV is the focus of this paper because it isolates the pricing of risk from concurrent factors such as the interest rate, the price of the underlying security, or daily wastage of the premium. Nonsynchronous closing quotes for the option and its underlying stock or index can bias the computation of IV. However, for three of the index option markets studied in this paper, the volume is among the highest in the world, which ensures that trading is thick and synchronous right up to the close of each day's trading.

TABLE 1

Descriptions of Four Stock Market Indices

Ticker

Symbol

Description

NYA New York Stock Exchange Composite. This capitalizationweighted index consists of all the stocks traded on the New York Stock Exchange. Futures contracts on the index are traded on the New York Futures Exchange.

OEX Standard \& Poor's 100 Index. This capitalization-weighted index consists of 100 large capitalization stocks. The futures contract on this index was unsuccessful.

SPX Standard \& Poor's 500 Index. This is a capitalizationweighted broad-based index, which serves as a benchmark portfolio in many financial situations. Futures contracts on the index are traded on the Chicago Mercantile Exchange. They are the most actively traded stock index futures contracts in the United States.

XMI American Stock Exchange Major Market Index. This priceweighted index consists of 20 very large capitalization stocks. Futures contracts on the index are actively traded on the Chicago Board of Trade. 
TABLE 2

Descriptions of 19 Individual Equities

\begin{tabular}{|c|c|c|c|c|c|c|}
\hline \multirow[b]{2}{*}{ Ticker } & \multirow[b]{2}{*}{ Company Name } & \multicolumn{4}{|c|}{$\%$ of Index } & \multirow[b]{2}{*}{ Industry } \\
\hline & & NYA & OEX & SPX & XMI & \\
\hline DD & DuPont & 1.13 & 2.91 & 1.36 & 7.64 & Chemicals \\
\hline DEC & Digital Equipment & 0.80 & 2.06 & 0.96 & $\mathrm{NA}$ & Computers \\
\hline DOW & Dow Chemical & 0.66 & 1.71 & 0.80 & 5.65 & Chemicals \\
\hline EK & Eastman Kodak & 0.80 & 2.06 & 0.96 & 5.75 & Imaging \\
\hline $\mathbf{F}$ & Ford & 1.03 & 2.64 & 1.24 & NA & Autos \\
\hline GE & General Electric & 2.04 & 5.24 & 2.45 & NA & Diversified \\
\hline GM & General Motors & 1.07 & 2.75 & 1.29 & 5.44 & Autos \\
\hline IBM & Int'l Bus Machines & 3.67 & 9.45 & 4.42 & 9.85 & Computers \\
\hline IP & Int'l Paper & NA & NA & $\mathrm{NA}$ & 2.98 & Paper \\
\hline JNJ & Johnson and Johnson & 0.62 & 1.60 & NA & 5.83 & Health \\
\hline $\mathrm{KO}$ & Coca Cola & 0.68 & 1.74 & 0.82 & 2.92 & Beverages \\
\hline MMM & Minnesota Mining & 0.64 & 1.63 & 0.76 & 4.51 & Diversified \\
\hline MO & Philip Morris & $\mathrm{NA}$ & NA & 1.06 & 6.02 & Tobacco \\
\hline MOB & Mobil & 0.81 & 2.09 & 0.98 & 3.21 & Oil \\
\hline MRK & Merck & 0.97 & 2.51 & 1.17 & 11.58 & Drugs \\
\hline PG & Proctor and Gamble & NA & NA & NA & 5.70 & Consumer Products \\
\hline S & Sears & 0.76 & 1.94 & 0.91 & 3.26 & Retailer \\
\hline WMT & Walmart & 0.79 & 2.04 & 0.95 & NA & Retailer \\
\hline $\mathrm{XON}$ & Exxon & 2.53 & 6.50 & 3.04 & 5.76 & Oil \\
\hline
\end{tabular}


IVs for calls (CIV) are computed using the Black and Scholes [2] model, adjusted for early exercise by subtracting the present value of expected dividends from the stock price, as in Cox and Rubinstein [11]. The use of the modified Black-Scholes model for calls was motivated by computational constraints. To validate this, extensive tests were performed on similar data. Results from the binomial model and from the modified BlackScholes model yielded nearly identical results. IVs for puts (PIV) are computed using the binomial model.

The IVs are volume-weighted combinations of between five and seven in-the-money, at-the-money, and out-of-the-money options. Wilson and Fung [49] find that IV is not significantly different over four weighting schemes:

1. At-the-money

2. Equal weights

3. Chiras and Manaster method [6]

4. Chiras [5]

The choice of a volume-weighted scheme is intended to limit the influence of stale, or nonsynchronous, quotes. The at-the-money option has the highest volume in the present data set. The resulting IV is dominated by that option, which is consistent with Beckers [1], as well as with the helpful comments of one of the referees.

As stated, expected dividends are used to examine the potential for early exercise. Many studies use historical dividends as if the market could forecast them exactly. This paper uses the dividend forecasts that were available on each trading day, similar to the Goldman Sachs IVs used in Stein [46]. The source of the dividend file is Options Research, Inc. (Berkeley, CA), which serves many market-makers on the four U.S. options exchanges.

\section{A Model of a Weekend Effect in IVs}

Buying a call and selling a put synthetically creates a long futures position. Buying a put and selling a call defines a synthetic short futures position. Studying the synthetic futures contract (SF) may help explain why the literature cited above and below fails to show that 
the exchange-traded futures contract (EF) shares the Monday decline typically observed in equity markets. Changes in the EF can be divided into changes in the theoretical value and changes in the premium (discount) to that theoretical value. This premium defines what is known as the "return-to-hedged portfolio" (RHP). The RHP is the return to index arbitrage as follows:

An investor sells (buys) the overvalued (undervalued) index, while buying (selling) the undervalued (overvalued) set of securities that compose the index. A positive return exists because the index and the associated futures contract converge at the expiration date of the futures.

If RHP systematically rises on Monday, it would offset the decline in the cash market and help explain the EF's lack of a Monday decline. An empirical analysis of the intraweek seasonality of RHP is deferred to subsequent research papers that access stock index futures data. This paper uses stock index options data to address the related questions raised by the behavior of the SF composed of call and put options on stock market indices.

The model states that changes in the relative pricing of calls and puts capture the essence of changes in RHP. RHP oscillates because EF varies from its theoretical value. Changes in RHP may correlate with changes in the relative pricing of the calls and puts that are combined to create the SF. Equation (1) states the relationship:

$$
\Delta(C I V-P I V)=f(\Delta R H P) .
$$

Morse [38] tests (1) and finds a correlation of about .47 between the dependent and the independent variables of (1). In a regression format, the 2.30 slope coefficient is significant at the .01 level, and the $R^{2}$ is .52 . Seasonality of either variable is not addressed in that paper.

If arbitrage forces SF to be highly correlated with $\mathrm{EF}$, then when RHP rises, calls are purchased and puts are sold. When RHP falls, calls are sold and puts are purchased. The relative pricing of calls and puts subsumes RHP, as demonstrated empirically in Morse [38]. 
Since IV serves as a way of stating the price of an option, the CIV less the PIV captures the relative pricing of calls and puts. At equilibrium, the quantity CIV -PIV is highly correlated with changes in RHP. The present paper analyzes CIV, PIV, and CIV - PIV. The strongest intraweek seasonality (or regularity) is found in the latter measure. Such a regularity, if one accepts equilibrium pricing of $\mathrm{EF}$ and $\mathrm{SF}$, helps explain the lack of intraweek seasonality observed in the traded futures markets. Although the underlying cash market may demonstrate a seasonal, the intraweek behavior of the futures contract may differ because its price is distorted by a subsidiary seasonal in the RHP. The observation here that CIV - PIV rises on Monday is consistent with arbitrageurs buying calls and selling puts, i.e., buying SF. If equilibrium between $\mathrm{EF}$ and $\mathrm{SF}$ holds, then EF will be biased upward on Monday because of positive changes in RHP. RHP rises, under the SF model, because it is correlated with changes in CIV - PIV. This offsets the effects of the lower price of the index itself on Monday.

If $\mathrm{EF}$ and $\mathrm{SF}$ are both influenced by a Monday rise in RHP, it is not anomalous to observe Monday cash declines without an accompanying fall in the futures market. Cornell [10] and Cinar and Vu [7] find just this, i.e., a cash market decline, but none in the futures contract. Consistent with this are Lauterbach and Monroe [34], who find that the S\&P 500 Index futures contract had low returns from Friday's close to Monday's open, offset by unusually high returns during Monday's trading hours. The present research is confined to testing for an intraweek seasonality in CIV - PIV. Future research will test for the possibility of simultaneous changes in RHP.

\section{Analysis}

Table 3 describes the IVs of index calls (CIV) and puts (PIV). In three of four cases, CIV is significantly less than PIV, as was also the case in Morse [38] for cash-settled index options and in Whaley [48] for options on index futures. Morse attributes the violation of putcall parity to a persistent discount in S\&P index futures 
TABLE 3

Four Stock Market Indices: Averages of Implied and Historical Volatilities (and Standard Deviations)

\begin{tabular}{lllll}
\hline & \multicolumn{1}{c}{ CIV } & \multicolumn{1}{c}{ PIV } & VOL21 & \multicolumn{1}{c}{ VOL63 } \\
\hline NYA* $^{*} .161(.036)$ & $.165(.043)$ & $.123(.036)$ & $.122(.027)$ \\
OEX $^{*}$ & $.163(.038)$ & $.165(.035)$ & $.144(.037)$ & $.142(.026)$ \\
SPX & $.163(.034)$ & $.165(.022)$ & $.133(.038)$ & $.131(.029)$ \\
XMI* & $.159(.045)$ & $.163(.045)$ & $.147(.042)$ & $.146(.033)$ \\
Average & .162 & .165 & .137 & .135 \\
\hline
\end{tabular}

*The difference between CIV and PIV is significant at the .05 level.

contracts over the study period. The connection between index futures and index options motivates the more precise model proposed above. As noted in Morse [39], bidask spreads, credit risk, and the probability of trading halts are all larger in down markets than in up markets. Thus, the grantor of options has higher expected hedging costs for puts than calls.

In three of four cases, the standard deviation of CIV is greater than that of PIV. For both calls and puts, XMI exhibits the smallest IV, which is curious because its IV is the highest.

Historical or trailing volatility (HV) is computed as the standard deviation of the natural logarithm of the daily price relative over 21 (VOL21) and 63 (VOL63) trading days. Stein [46] states that traders often use HV based on 20- to 30-day periods. In all four cases, IV exceeded HV by a considerable margin. For example, the difference between CIV and VOL21 is significant at the .01 level for all four indices. For PIV less VOL21, the results are the same. XMI is the most volatile, which is likely because the component stocks trade thickly compared with the broader based indices, which contain stale quotes.

The opposite bias prevails in the equity options. For these, CIV is higher than PIV. Table 4 contains CIV, PIV, and HV for the 19 stocks. Note that unlike the index results, CIV exceeds PIV for all cases except PG and XON. Presumably, arbitrage strategies such as conversions and reverse conversions are more facile in equi- 
TABLE 4

Averages of Implied and Historical Volatilities (Standard Deviations) of Options on 19 Stocks

\begin{tabular}{lcccc}
\hline Stocks & CIV & PIV & VOL21 & VOL63 \\
\hline DD & $.230(.046)$ & $.223(.040)$ & $.223(.064)$ & $.224(.051)$ \\
DEC & $.313(.038)$ & $.308(.036)$ & $.282(.059)$ & $.279(.032)$ \\
DOW & $.248(.040)$ & $.229(.034)$ & $.231(.053)$ & $.231(.036)$ \\
EK & $.249(.057)$ & $.231(.047)$ & $.234(.069)$ & $.231(.050)$ \\
F & $.274(.046)$ & $.259(.038)$ & $.272(.068)$ & $.272(.048)$ \\
GE & $.224(.049)$ & $.215(.043)$ & $.225(.059)$ & $.221(.042)$ \\
GM & $.226(.027)$ & $.210(.025)$ & $.217(.045)$ & $.217(.026)$ \\
IBM & $.214(.036)$ & $.199(.031)$ & $.195(.045)$ & $.193(.030)$ \\
IP & $.266(.064)$ & $.250(.054)$ & $.245(.084)$ & $.241(.069)$ \\
JNJ & $.256(.035)$ & $.239(.030)$ & $.253(.061)$ & $.256(.041)$ \\
KO & $.251(.070)$ & $.243(.059)$ & $.237(.082)$ & $.233(.071)$ \\
MMM & $.212(.048)$ & $.200(.039)$ & $.189(.056)$ & $.188(.040)$ \\
MO & $.244(.069)$ & $.235(.047)$ & $.247(.084)$ & $.246(.062)$ \\
MOB & $.243(.038)$ & $.232(.028)$ & $.257(.071)$ & $.262(.042)$ \\
MRK & $.241(.059)$ & $.228(.048)$ & $.211(.071)$ & $.210(.057)$ \\
PG & $.205(.055)$ & $.209(.036)$ & $.218(.058)$ & $.218(.044)$ \\
S & $.253(.040)$ & $.237(.034)$ & $.256(.066)$ & $.259(.049)$ \\
WMT & $.303(.044)$ & $.291(.028)$ & $.283(.069)$ & $.281(.049)$ \\
XON & $.189(.029)$ & $.190(.021)$ & $.208(.046)$ & $.208(.024)$ \\
Average & .244 & .233 & .236 & .235 \\
\hline
\end{tabular}

ties. As reported above for index options (as well as in Morse [38]), the standard deviation of equity calls is greater than that of puts.

For indices, IV was several percentage points above $\mathrm{HV}$, which may reflect demand for portfolio insurance during the sample period. For equities, Table 4 notes that CIV and PIV are very close to VOL21 and VOL63, possibly because of the relative ease of arbitrage in individual stocks.

Average CIV(indices) exceeds CIV(equities) by 8.2 . PIV(indices) exceeds PIV(equities) by 6.8 . These spreads are consistent with longer term estimates reported by Wall Street firms. The spread between index options and stock options exists because a call on an index is less valuable than a set of calls on each individual element of the index. 
During the study period, the market, as measured by all four indices, rose by about 85 percent. Dividends concentrate in certain months (see CBOT [3]), but it is unlikely that analysis of daily changes is distorted. Since short-term variations are likely to be dwarfed by these trends, the first differences of each data series are computed. This materially lessens autocorrelation in the sample data and reduces the chance of biased statistics and tests. The first (differenced) observation is interpreted as the IV at time $t$ minus the IV at time $t-1$. For example, Friday's number is Friday's IV less Thursday's. Monday's number is Monday's less Friday's. A positive Friday first difference is interpreted as Friday IV's excess over Thursday IV. The reversal (i.e., a negative Monday number) means that IV fell on Monday. The first differences of calls are noted DIFCIV, while DIFPIV refers to puts. CIV and PIV relative to each other are seen through the difference of the first differences, i.e., DIFCIV - DIFPIV.

The first columns of Tables $5 a-5 c$ present $F$-tests that examine the hypothesis that all daily means of first differences are equal. In general, the null hypothesis cannot be rejected for index calls in isolation. For puts, the null hypothesis is rejected in three of four cases. Table 5 c shows significant $F$ s for the relative behavior of calls and puts (DIFCIV - DIFPIV) in OEX and NYA. It is possible that the $F$-test fails for SPX because volume in that option was about 5 percent of OEX volume

TABLE $5 a$

DIFCIV: First Differences of Call Implied Volatility

\begin{tabular}{lcccccc}
\hline & F-Sig & FRI-Down & MON-Up & M, F Var* & MID & \#SIG*** \\
\hline NYA & 2.26 & Yes & No & Yes & Yes & 3 \\
OEX & 1.37 & Yes & Yes & Yes & Yes & 1 \\
SPX & 2.15 & No & Yes & No & No & 3 \\
XMI & 1.21 & No & Yes & Yes & Yes & 1 \\
\hline
\end{tabular}

*Variance of IV is highest on Monday or Friday.

**At least two midweek days are negative.

***Number of days significantly different from Monday or Tuesday.

*****Significant at the .05 level. 
TABLE $5 b$

DIFPIV: First Differences of Put Implied Volatility

\begin{tabular}{llccccc}
\hline & $F$-Sig & FRI-Up & MON-Down & M, F Var* & MID** & \#SIG*** \\
\hline NYA & $4.57^{* * * * *}$ & Yes & Yes & Yes & Yes & 4 \\
OEX & $6.32^{* * * *}$ & Yes & Yes & No & Yes & 5 \\
SPX & 1.19 & Yes & Yes & Yes & Yes & 1 \\
XMI & $2.69^{* * * *}$ & Yes & Yes & Yes & Yes & 3 \\
\hline
\end{tabular}

*Variance of IV is highest on Monday or Friday.

**At least two midweek days are negative.

***Number of days significantly different from Monday or Tuesday.

****Significant at the .05 level.

TABLE 5c

DIFCIV - DIFPIV: First Differences of CIV Less First Differences of PIV

\begin{tabular}{lcccccc}
\hline & $F$-Sig & \multicolumn{2}{c}{ FRI-Down } & MON-Up & M, F Var* & MID \\
& & \# & SIG*** \\
\hline NYA & $4.07^{* * * *}$ & Yes & Yes & Yes & Yes & 5 \\
OEX & $4.87^{* * * *}$ & Yes & Yes & Yes & Yes & 5 \\
SPX & .20 & Yes & Yes & Yes & No & 0 \\
XMI & .45 & Yes & Yes & Yes & Yes & 0 \\
\hline
\end{tabular}

*Variance of IV is highest on Monday or Friday.

**At least two midweek days are negative.

$* * *$ Number of days significantly different from Monday or Tuesday.

$* * * *$ Significant at the .05 level.

during the sample period. Low volume exacerbates nonsynchronous pricing and erratic quotes.

The first column ( $F$-Sig), the second column (FRIDown/Up), and the third column (MON-UP/Down) show whether IV moves as we would expect it to if the synthetic futures contract mimics the traded futures contract's lack of a Monday decline. Monday CIV - PIV should rise, as the futures RHP increases.

The results for index calls in Table 5a are mixed. The broad-based indices NYA and OEX behave as expected on Friday. SPX does not, possibly because of the low volume noted above. XMI also fails to drop on Friday, possibly due to a similarity with equity options, 
which will be described below. Monday behaves as expected in three of four cases. For puts (Table 5b), three $F$-tests are significant. Friday IV rises and Monday IV declines for all four indices. DIFCIV - DIFPIV (Table $5 c)$ behaves uniformly as expected under the model proposed in this paper. Monday CIV - PIV does rise as postulated. That Friday CIV - PIV declines is gratuitous. It is consistent with the strong Fridays that the cited literature occasionally documents. However, since the Friday effect is not as pervasive as the Monday effect, further comments are not useful.

The latter columns of Tables 5a-5c suggest three indirect ways to confirm that something is different about weekends. The fourth column (M,F Var) shows whether or not the highest variance of the IV series occurred on either a Monday or a Friday. This is almost always the case for Tables 5a-5c in the case of index options. The pattern brackets the weekend and distinguishes it from midweek. A seasoning process may surround the weekend, as hedges are adjusted before and after the trading interruption.

According to Foster and Viswasnathan [22], adverse selection costs are highest on Monday because information has accumulated without being reflected in prices. Uninformed traders are motivated to delay their trades. The volume rises through the week, and price variance is highest on Monday. Although Monday is not uniformly the day of highest variance of IVs, either Friday and Monday is normally the highest IV variance day. Jaffe and Westerfield [29] found that Monday returns were the lowest for equities in five countries; that day also had the highest variance of returns. The pattern of IV may be correlated contemporaneously with the volatility of the underlying index.

The final column documents whether at least two midweek days (i.e., Tuesday, Wednesday, and Thursday) show a drop in IV after the weekend. The contention that weekends are different is strengthened if midweek return variance and IV are lower. For Tables 5a-5c, we see this happening in three out of four indices. Two of the three negatives are associated with the very thinly traded SPX option. The midweek reversal is associated 
with the time of the week in which the cash markets also fail to exhibit seasonality.

One-way analysis of variance (ANOVA) tests for significant differences among days. The independent (or treatment) variable is the day of the week, and IV is the dependent variable. The Fisher Protected Least Significant Difference test is used, as described in Winer [50] and Koopmans [32]. ANOVA results appear in the sixth column, which counts the number of significant pairwise differences of a weekday versus a Friday or a Monday among the first differences of the IVs. Here again is evidence of a weekend effect, especially with the broadbased and thickly traded NYA and OEX. The effect in $\mathrm{XMI}$ is less pronounced. This index is composed of only 20 stocks; it appears to behave more like the options on individual equities, which are described below. The particular behavior of XMI may occur because it is the only index that can be bought and sold almost as easily as individual equities for conversions and reverse conversions. The index basket (i.e., the properly weighted set of securities) is routinely quoted by dealers in the United States and in early morning trading in London. Further liquidity and arbitrage services are available through the futures contract, which is actively traded on the Chicago Board of Trade.

Since Morse [38] finds that index options and individual equity options did not behave similarly, Table 6 extends the search for a weekend effect to 19 individual stock options. For the first differences, the postulated down effect is not evident. Perhaps put-call parity is more stable because conversions and reverse conversions are relatively easy.

The high weekend variability hypothesis is supported by the fourth column, as is the downward IV during midweek in the fifth column. The pairwise differences tabulated in the last column are not, in general, significant.

In sum, equity IVs lack the regularities observed in index options. There is scant evidence of different behavior before and after the weekend. Statistical tests may fail because equity option volume is considerably smaller than index option volume. Transaction-level 
TABLE 6

Various Characteristics of Equity Options

DIFCIV - DIFPIV: First Differences of CIV Less First Differences of PIV

\begin{tabular}{|c|c|c|c|c|c|c|}
\hline & $F$-Sig & FRI-Down & MON-Up & $\mathbf{M}, \mathbf{F} \operatorname{Var}^{*}$ & $\mathrm{MID}^{* *}$ & $\# \mathrm{SIG}^{* * *}$ \\
\hline DD & 0.08 & Yes & Yes & Yes & Yes & 0 \\
\hline DEC & 0.67 & No & No & Yes & No & 0 \\
\hline DOW & 0.96 & No & No & No & Yes & 0 \\
\hline EK & 0.17 & No & No & No & No & 0 \\
\hline $\mathbf{F}$ & $3.65 * * * *$ & No & Yes & No & Yes & 4 \\
\hline $\mathrm{GE}$ & 1.23 & No & Yes & No & No & 1 \\
\hline GM & $3.57 * * * *$ & No & No & Yes & Yes & 3 \\
\hline IBM & 0.47 & No & No & No & No & 0 \\
\hline IP & 1.76 & No & Yes & Yes & Yes & 2 \\
\hline JNJ & 2.37 & No & Yes & No & Yes & 3 \\
\hline KO & 0.75 & No & Yes & No & Yes & 0 \\
\hline MMM & 1.86 & No & Yes & No & Yes & 2 \\
\hline MO & 0.59 & Yes & No & Yes & Yes & 0 \\
\hline MOB & 1.33 & No & No & Yes & No & 0 \\
\hline MRK & 1.14 & No & Yes & Yes & Yes & 0 \\
\hline PG & 1.30 & Yes & No & Yes & No & 0 \\
\hline S & 1.14 & No & No & Yes & Yes & 0 \\
\hline WMT & 0.24 & No & No & Yes & No & 0 \\
\hline \multirow[t]{2}{*}{$\mathrm{XON}$} & 1.13 & No & No & No & No & 0 \\
\hline & $\#$ Sig $=1$ & $\#$ Yes $=3$ & $\#$ Yes $=8$ & $\#$ Yes $=10$ & $\#$ Yes $=11$ & $3^{* * * * *}$ \\
\hline
\end{tabular}

*Variance of IV is highest on Monday or Friday.

**At least two midweek days are negative.

***Number of days significantly different from Monday or Tuesday.

****Significant at the .05 level.

*****N Number of significant paired comparisons. 
data for one month on all stocks with options traded on the Chicago Board Options Exchange were obtained.

Most of the options did not trade thickly right up to closing, as OEX does. Thus nonsynchronous data are probably a confounding influence. There was a rough correspondence between option volume and the level of significance. Hence there are more frequent occurrences of nonsynchronous trading and high bid-ask spreads, and thin trading. Spreads are not firm in the face of orders in excess of 20 contracts. In addition, arbitrage is easier for individual equities. The resultant tendency toward put-call parity smooths interday regularities. Perhaps for these reasons, Morse [38] finds that changes in the IVs of index options do not correlate highly with changes in equity option IVs.

The indices underlying the index options are analyzed. Daily cash returns of the four indices were about the same. The variance of XMI was the highest, as was that of its CIV and PIV (Table 3). This index comprises 20 components, and all are large capitalization, thickly traded companies. XMI may have the highest variability because it has the least (described in papers on the intervalling effect by Cohen et al. [8] and Larson and Morse [33]) problem with stale prices for index components.

Of the four sets of index cash returns, only NYA showed a negative Monday return. The returns of the 19 stocks in the sample are also analyzed. There were no significant interday regularities, which is not surprising given the similar index results. The 19 stocks were all large firms.

The lack of seasonality is not surprising, since the received literature on U.S. stock markets does not demonstrate a weekend effect in all subperiods. Fishe, Gosnell, and Lasser [20] note that the Monday effect is mainly evident during down markets. Liano and Gup [35] find the same for business cycles. The stock market rose substantially during the sample period. PhillipsPatrick and Schneeweis [41] also fail to confirm a Monday effect for value-weighted indices during 1981-1985. In SPX, Monday returns were the lowest of the week. Thus the two indices that are highly influenced by small firms do show Monday returns that are negative or at 
least lower than other weekdays. This is consistent with Keim and Stambaugh [31] who find that the upward slope in returns from Monday through Friday was more obvious for small firms. As expected, Friday returns were all up, although not significantly so. A relationship between size and Friday returns, as suggested by Keim and Stambaugh [31], is not evident.

Dickinson and Peterson [14] find that call options fall on Monday and, surprisingly, that put options do not rise significantly. The results of the present paper are consistent with their results, since IV can be viewed as a price. Using IV facilitates the analysis of the intraweek differences between stock index calls and puts (i.e., CIV - PIV). The synthetic futures model suggested here helps explain why Dickinson and Peterson do not find that puts rise on Monday. The rise in the intrinsic value of puts is weakened by a drop in their IV.

\section{Summary and Conclusions}

Although the tendency of equities to decline on Monday has been widely documented, anomaly researchers often fail to confirm a corresponding Monday effect in stock index futures trading. By defining and then decomposing a synthetic futures contract created from options, the different results in the cash and the futures market may be better understood. This paper initiates the study of intraweek seasonalities in the implied volatilities of options on stock market indices. During the period of November 19, 1984, through July 10, 1987, this paper documents intraweek seasonalities in the implied volatility of options on stock market indices. The observed patterns are consistent with cited results in the futures markets.

One-way analysis of variance isolates the daily behavior of implied volatilities. For index options, the difference between call implied volatility and put implied volatility tends to drop on Friday and rise Monday. The phenomenon is examined in the context of a model based on a synthetic futures contract. For options on individual equities, no similar day-of-the-week implied volatility effects are evident. 
Among minor observations, the implied volatility of calls is less than that of puts in index options, while the reverse is true for options on individual equities. The standard deviation of call implied volatility is generally greater than that of puts.

For both indices and equities, implied volatility usually drops on Tuesday, Wednesday, and Thursday. Its variance tends to be highest on Fridays and Mondays. These results are reminiscent of Foster and Viswasnathan [22], whose model is derived from distinct interday levels of adverse selection costs.

For index options, implied volatility is markedly higher than two measures of historical volatility. For equity options, implied volatility is very close to historical volatility. The pricing of index options may reflect either sample-specific demand for portfolio insurance or hedging costs for (short) writers.

Presumably, arbitrage strategies such as conversions and reverse conversions are more facile in equities. The phenomenon of a weekend effect in equity markets can be studied in the context of stock index options and futures markets. Isolating the return-to-hedged portfolio and the relative levels of implied volatility of calls and puts may help explain the different intraweek price patterns observed in equity derivatives and their underlying markets.

Future research is indicated to test for the postulated rise in the return-to-hedged portfolio in the futures markets. Using intraday data to attribute the main effects observed in this paper to particular times of the day is also appropriate.

\section{References}

[1] Beckers, Stan. "Standard Deviations Implied in Options Prices as Predictors of Future Stock Price Variability." Journal of Banking and Finance 5(September 1981):363-381.

[2] Black, Fischer, and Myron Scholes. "The Pricing of Options and Corporate Liabilities." Journal of Political Economy 81(May/ June 1973):637-659.

[3] CBOT. "Stock Index Futures and Dividend Seasonality." Working Paper, Chicago Board of Trade, April 1989. 
[4] Chiang, Raymond C., and T. Craig Tapley. "Day-of-the-Week Effects and the Futures Market." Review of Research in Futures Markets 2(October 1983):356-410.

[5] Chiras, Donald P. "Predictive Characteristics of Standard Deviation of Stock Returns Inferred from Option Prices." Ph.D. diss. Gainesville: University of Florida, 1977.

[6] Chiras, Donald P., and Steven Manaster. "The Information Content of Options Prices and a Test of Market Efficiency." Journal of Financial Economics 6(June/September):213-234.

17] Cinar, E. Mine, and Joseph D. Vu. "Seasonal Effects in the Standard \& Poor's 500 and Value Line Cash and Futures Returns." Working Paper, Loyola University of Chicago, 1989.

[8] Cohen, Kalman J., Gabriel A. Hawawini, Steven F. Maier, Robert A. Schwartz, and David K. Whitcomb. "Estimating and Adjusting for the Intervalling-Effect Bias in Beta." Management Science 29(January 1983):135-148.

[9] Connally, Robert A. "A Posterior Odds Analysis of the Weekend Effect." Working Paper, University of California-Irvine, June 1988.

[10] Cornell, Bradford. "The Weekly Pattern in Stock Returns: Cash versus Futures: A Note." Journal of Finance 40(June 1985):583-588.

[11] Cox, John C., and Mark Rubinstein. Options Markets. Englewood Cliffs, NJ: Prentice-Hall, 1985.

[12] Day, Theodore E., and Craig M. Lewis. "The Behavior of the Volatility Implicit in the Prices of Stock Index Options." Working Paper, University of North Carolina, February 1988.

[13] De Gennaro, Ramon P. "The Effect of Payment Delays on Stock Prices." Journal of Financial Research 13(Summer 1990):133145.

[14] Dickinson, Amy, and David R. Peterson. "Seasonality in the Option Market." The Financial Review 24(November 1989):529540 .

[15] Dimson, Elroy, ed. Stock Market Anomalies, Cambridge, England: Cambridge University Press, 1988.

[16] Dyl, Edward A. "Profits and Patterns in the Federal Funds Market." Burroughs Clearing House 56(April 1977):60-62.

[17] Dyl, Edward A., and Edwin D. Maberly. "The Daily Distribution of Changes in the Price of Stock Index Futures." Journal of Futures Markets 6(Winter 1986):513-521.

[18] Eisemann, Peter C., and Stephen G. Timme. "Intraweek Seasonality in the Federal Funds Market." Journal of Financial Research 7(Spring 1984):47-56. 
[19] Finnerty, Joseph E., and Hun Y. Park. "Intraday Return and Volatility Patterns in the Stock Market: Futures versus Spot." Advances in Futures and Options 3(1988):301-317.

[20] Fishe, Raymond P. H., Thomas Gosnell, and Dennis J. Lasser. "Good News, Bad News, Volume, and the Monday Effect." Working Paper, University of Miami, September 1989.

[21] Flannery, Mark J., and Aris A. Protopapadakis. "From T-Bills to Common Stocks: Investigating the Generality of Intra-Week Return Seasonality." Journal of Finance 43(June 1988):431450.

[22] Foster, F. Douglas, and S. Viswasnathan. "Variations in Volumes, Variances, and Trading Costs." Working Paper, Duke University, June 1989.

[23] Foster, F. Douglas, and S. Viswasnathan. "A Theory of Interday Variations in Volumes, Variances and Trading Costs in Securities Markets." Working Paper, Duke University, 1989.

[24] Gay, Gerald D., and Tae-Hyuk Kim. "An Investigation into Seasonality in the Futures Market." Journal of Futures Markets 7(Summer 1987):169-181.

[25] Gibbons, Michael R., and Wayne Ferson. "Testing Asset Pricing Models with Changing Expectations and an Unobservable Market Portfolio." Journal of Financial Economics 14(June 1985):217-236.

[26] Harris, Lawrence. "A Transaction Data Study of Weekly and Intradaily Patterns in Stock Returns." Journal of Financial Economics 16(May 1986):99-117.

[27] Huang, Roger D. "An Analysis of Intertemporal Pricing for Forward Foreign Exchange Contracts." Journal of Finance 44(March 1989):183-194.

[28] Jaffe, Jeffrey, and Randolph Westerfield. "Patterns in Japanese Common Stock Returns: Day of the Week and Turn of the Year Effects." Journal of Financial and Quantitative Analysis 20(June 1985a):261-272.

[29] Jaffe, Jeffrey, and Randolph Westerfield. "The Week-End Effect in Common Stock Returns: The International Evidence." Journal of Finance 40(June 1985b):433-454.

[30] Johnston, Elizabeth Tashjian, William A. Kracaw, and John J. McConnell. "Day-of-the-Week Effects in Financial Futures: An Analysis of GNMA, T-Bond and T-Bill Contracts." Working Paper, University of Utah, May 1987.

[31] Keim, Donald B., and Robert F. Stambaugh. "A Further Investigation of the Weekend Effect in Stock Returns." Journal of Finance 39(July 1984):819-840.

[32] Koopmans, Lambert H. Introduction to Contemporary Statistical Methods. Boston: Duxbury Press, 1987. 
[33] Larson, John C., and Joel N. Morse. "Intervalling Effects in Hong Kong Stocks." Journal of Financial Research 10(Winter 1987):353-362.

[34] Lauterbach, Beni, and Margaret Monroe. "A Transaction Data Examination of the Weekend Effect in Futures Markets." Working Paper No. 23, University of Illinois at Chicago, 1989.

[35] Liano, Kartono, and Benton E. Gup. "The Day-of-the-Week Effect in Stock Returns over Business Cycles." Financial Analysts Journal 45(July/August 1989):74-77.

[36] Ma, Christopher K., Ramesh P. Rao, and Herbert J. Weinraub. "The Seasonality in Convertible Bond Markets." Journal of Financial Research 11(Winter 1988):335-347.

[37] Melton, William C. Inside the Fed. Homewood, IL: Dow JonesIrwin, 1985.

[38] Morse, Joel N. "Index Futures and the Implied Volatility of Options." Review of Futures Markets 7(1988):325-333.

[39] Morse, Joel N. "An Intraweek Seasonality in the Implied Volatilities of T-Bonds and T-Note Options." Global Finance Journal (forthcoming 1991).

[40] Peterson, David R. "A Transaction Data Study of Day-of-theWeek and Intraday Patterns in Option Returns." Journal of Financial Research 13(Summer 1990):117-132.

[41] Phillips-Patrick, Frederick J., and Thomas Schneeweis. "The 'Weekend Effect' for Stock Indexes and Stock Indexes Futures: Dividend and Interest Rate Effects." Journal of Futures Markets 8(February 1988):115-121.

[42] Poole, William. "Commercial Bank Reserve Management in a Stochastic Model: Implications for Monetary Policy." Journal of Finance 23(December 1968):769-791.

[43] Porter, David C. "The Probability of a Trade at the Ask: An Examination of Interday and Intraday Behavior." Working Paper, Marquette University, May 1989.

[44] Rystrom, David S., and Earl D. Benson. "The Day-of-the-Week Effect, Blue Mondays, and Evidence from Odd-Lot Trading." Working Paper, Western Washington University, September 20,1989 .

[45] Spindt, Paul A., and J. Ronald Hoffmeister. "The Micromechanics of the Federal Funds Market: Implications for Day-of-theWeek Effects in Funds Rate Variability." Journal of Financial and Quantitative Analysis 23(December 1988):401-416.

[46] Stein, Jon. "Why Options Traders Focus on Volatility over Price." Futures 18(August 1989):32-33.

[47] Stigum, Marcia L. The Money Market. Homewood, IL: DowJones Irwin, 1983. 
[48] Whaley, Robert E. "Valuation of American Futures Options: Theory and Empirical Evidence." Journal of Finance 41(March 1986):127-150.

[49] Wilson, William W., and Hung-Gay Fung. "Put-Call Parity and Arbitrage Bounds for Options on Grain Futures." American Journal of Agricultural Economics 42(February 1991):55-65.

[50] Winer, B. J. Statistical Principles in Experimental Design, New York: McGraw-Hill, 1971.

[51] Ziemba, William T. "Seasonality Effects in Japanese Futures Markets." Working Paper, University of British Columbia, 1989. 